\title{
THE PREDISPOSING FACTORS OF PIRIFORMIS SYNDROME: STUDY IN A REFERRAL HOSPITAL
}

\author{
Yusak Mangara Tua Siahaan ${ }^{1}$, Retno Jayantri Ketaren ${ }^{1}$, Vinson Hartoyo ${ }^{1}$, Pamela Tiffani ${ }^{1}$ \\ Correspondence: dryusaks2002@gmail.com \\ ${ }^{I}$ Department of Neurology Faculty of Medicine Pelita Harapan University, Tangerang, Indonesia.
}

\section{Article History:}

Received: October 23, 2018

Accepted: March 5, 2019

Published: July 1, 2019

\section{Cite this as:}

Siahaan YMT, Ketaren RJ,

Hartoyo $V$, Tiffani P. The

predisposing factors of piriformis

syndrome: study in a referral

hospital. Malang Neurology

Journal; 2019.5:76-79. DOI:

http://dx.doi.org/10.21776/ub.mnj .2019.005.02.5

\section{ABSTRACT}

Background: Piriformis syndrome is a neuromuscular condition characterized by hip and gluteal pain caused by abnormality of piriformis muscle. In clinical practice, this syndrome is usually misdiagnosed with other spinal disorders. There is no specific test in diagnosing piriformis syndrome, therefore by understanding the characteristics and predisposing factors, clinicians may be more aware in diagnosing this syndrome.

Objective: To investigate the characteristics and predisposing factors of piriformis syndrome.

Methods: A descriptive study was conducted on patients with gluteal pain in a referral hospital. Diagnosis was established by block injection on piriformis muscle and showed clinical improvement afterwards. Demographic characteristics, predisposing factors, and physical examination were analyzed. The data is collected and processed by SPSS 20.0.

Results: The total of 65 patients were evaluated, with a male to female ratio 1:3. As much as $47.7 \%$ of patients were $>60$ years old. Average weight was $60 \mathrm{~kg}$ and BMI (Body Mass Index) was within normal range $(58.9 \%)$. Most subjects were housewives $(55.4 \%)$ and the majority of subjects had history of microtrauma such as sitting on rigid surfaces (36.9\%), walking or running long distances $(18.5 \%)$, and cross-legged sitting $(10.8 \%)$. Average sitting per day was approximately 5 hours. In $56.9 \%$ of subjects, exercises were conducted. There was no history of back pain in $81.5 \%$ of subjects. Conclusion: Our study showed age and housewives characteristics differ with other studies. The most predisposing factors were history of microtrauma, female, age, and normal BMI.

Keywords: Characteristic, Piriformis syndrome, Predisposing factor

\section{Introduction}

Piriformis syndrome is a peripheral neuritis that is caused by either hypertrophy, inflammation, or anatomical variation of piriformis muscle resulting strangulated and irritated of sciatic nerve. ${ }^{1}$ Piriformis syndrome is mostly seen in the fourth to fifth decade, with female predominance in a ratio of 6 to 1 . Prevalence of piriformis syndrome is estimated between 12.2 to $27 \%$. $^{2}$ Etiology of this syndrome is divided into primary and secondary causes. Primary piriformis syndrome is related to the anatomical location of piriformis muscle and sciatic nerve with occurrence in $15 \%$ of cases whereas secondary piriformis syndrome is caused by repetitive precipitating factors, including microtrauma, macrotrauma, and local ischemia. ${ }^{2}$ History of trauma in the pelvic and gluteus regions is a predisposing factor that is often obtained as a trigger for piriformis syndrome. Some individuals who have a high risk of secondary piriformis syndrome are skiers, tennis players, and long distance bicycle athletes. ${ }^{3}$

Piriformis syndrome patients complain of pain in the gluteus area which generally radiates to the lower limbs that may be accompanied by paresthesia, hyperesthesia, and muscle weakness. However, the associated symptoms often indicate a delay in the diagnosis of piriformis syndrome. Delayed diagnosis of piriformis syndrome might lead to various pathologic conditions of sciatic nerve, chronic somatic dysfunction, and compensatory pain. In serious cases, misdiagnosis lead to unnecessary surgery in prolapsed intervertebral disc. ${ }^{4}$ The biggest problem of clinical diagnosis of piriformis syndrome is the absence of a specific and consistent test in diagnosing piriformis syndrome. Confirmation of the diagnosis is also as a treatment of piriformis syndrome is imaging guided block injections done by a skilled clinician. Therefore, discovering the characteristics and predisposing factors is expected to aid the primary clinician in sharpening the diagnosis of piriformis syndrome.

\section{Methods}

A total of 65 patients with complaints of buttock pain in the period from August to December 2017 were performed history taking and physical examination. History taking is taken by one researcher about demographic characteristics (age, gender, BMI, job) and clinics related to piriformis syndrome, then the physical examination such as piriformis point and provocative test (FAIR, Freiberg, Beatty, Pace, and Hip Abduction) is done by other researcher. The diagnosis of piriformis syndrome was confirmed by ultrasound guided diagnostic block injection with corticosteroid and lidocaine or lidocaine only by skilled 
clinicians. Data was collected and processed using SPSS version 20.0 as a descriptive study.

\section{Results}

Sixty five patients that were diagnosed with piriformis syndrome were evaluated. The characteristics (age, gender, BMI, and occupation) of piriformis syndrome showed result that the highest prevalence in the age group are elderly aged 60 years and above with percentage of $47.7 \%$, followed by 50-59 year old groups, 40-49 year old groups, and 20-39 year old groups while in gender, piriformis is dominated by female than male with ratio of $3: 1$. The average body weight was $60(45-66.8 \mathrm{~kg})$ and the Body Mass Index (BMI) was dominated by the normal category $(58.9 \%)$. Most of the samples were housewives $(55.4 \%)$ followed by field workers $(29.2 \%)$, office workers $(13.8 \%)$ and others unemployed (1.5\%).

Table 1. Characteristics of piriformis syndrome.

\begin{tabular}{lcc}
\hline \multicolumn{1}{c}{ Characteristic } & Frequency (n) & Percentage (\%) \\
\hline Age & 4 & 6.2 \\
$20-39$ & 11 & 16.9 \\
$40-49$ & 19 & 29.2 \\
$50-59$ & 31 & 47.7 \\
$>60$ & & \\
Gender & 17 & 26.2 \\
Male & 48 & 73.8 \\
Female & & \\
Body Mass Index & 1 & 1.5 \\
Underweight (<18.5) & 37 & 58.9 \\
Normal (18.5-24.9) & 23 & 35.4 \\
Overweight (25-29.9) & 4 & 6.2 \\
Obese ( $\geq 30)$ & & \\
Job & 1 & 1.5 \\
Jobless & 36 & 55.4 \\
Housewives & 9 & 13.8 \\
Office worker & 19 & 29.2 \\
Field worker & & \\
Clinical Features & 65 & 100.0 \\
Buttock pain & 62 & 95.4 \\
Piriformis point & 56 & 86.1 \\
Provocative test (min 2) & 65 & 100.0 \\
Diagnostic block & &
\end{tabular}

Table 2. Predisposing factors of Piriformis sydrome.

\begin{tabular}{lcc}
\hline \multicolumn{1}{c}{ Risk Factor } & Frequency (n) & Percentage (\%) \\
\hline Microtrauma history & 22 & 33.8 \\
None & 12 & 18.5 \\
Walking/ running long distances & 7 & 10.8 \\
Cross-legged sitting & 24 & 36.9 \\
Sitting on firm surface & & \\
Sitting history (duration per day) & 12 & 18.5 \\
0-2 hours/ day & 22 & 33.8 \\
3-5 hours/ day & 31 & 47.7 \\
6-8 hours/ day & & \\
Frequency of fast walking/ running activity & 28 & 43.1 \\
0-1x/ week & 32 & 49.2 \\
2-3x/ week & 5 & 7.7 \\
4-5x/ week & & \\
Back pain history & 53 & 81.5 \\
None & 6 & 9.2 \\
HNP & 3 & 4.6 \\
Piriformis & 3 & 4.6 \\
Other & & \\
\hline
\end{tabular}


Most patients had a history of microtrauma by sitting on rigid surfaces $(36.9 \%)$, walking or running long distances $(18.5 \%)$, and sitting cross-legged regularly (10.8\%) although there were $33.8 \%$ without a history of microtrauma. The average of continous regularly sitting per day was approximately 1-9 hours, with the majority patients of $47.7 \%$ in the history of sitting with duration of 6-8 hours per day. Most patients conducted fast walking or running activity 2 to 3 times per week with average data about 1-5 times per day. $81.5 \%$ patients had no history of previous low back pain, while $18.5 \%$ had a history of low back pain, whereas 9.2\% having herniated nucleus pulposus (HNP), $4.6 \%$ had piriformis syndrome and $4.6 \%$ had a history of low back pain due to other disorders.

\section{Discussion}

The incidence and prevalence of piriformis syndrome are still unknown, but it is estimated that prevalence rate is very diverse and ranges from 6 to $36 \%$, influenced by the diagnostic criteria used and the characteristics of the sample population. Piriformis syndrome occurs most often at the age of 40-60 years and is obtained with various activities and occupations. Other studies showed different onset of piriformis syndrome that in the third to fourth decade of age, based on the study by Danilo et al which states that the majority occur at an average age of 38 years. ${ }^{3}$ The report is similar with the results of Jawish's research et al who reported the average age of patients with piriformis syndrome was 35.37 years and Mondal et al at the age of 32.3 years. ${ }^{4,5}$ Whereas Hopayian et al reported the average age of patients with piriformis syndrome in each study was 43 years. ${ }^{5}$ In this study, there was a difference in the average age of patients with several previous studies which the age more than 60 years became the group with the largest proportion suffering from piriformis syndrome (47\%) followed by the age group 50-59 years (29\%) while in the age group 20 - 39 years, affects $6.2 \%$ of patients only. Although this study mostly included elderly patients (more than 60 years), there are no data support age as the independent variable of piriformis syndrome. Majority studies assume this syndrome is affected by age and anatomical changes. ${ }^{3,5}$

Previous studies have shown that female suffer more from piriformis syndrome than male, although with varying proportions, Danilo et al found a ratio of female compared to male 6: 1 , Chen et al reported a ratio of $3: 2 .^{3,6}$ Predisposing female in piriformis syndrome may be caused by anatomical angle of the quadriceps femoris muscle in the women pelvis is wider than men. ${ }^{7}$ Other studies reported that hormonal changes in women especially during pregnancy can also affect the occurrence of piriformis syndrome. ${ }^{8}$ Microtrauma in the buttocks may induce inflammation of the soft tissue which results in nerve compression. ${ }^{1}$ In this study we examined the predisposing factors including BMI and history of exposure such as occupation, sitting duration, physical activity frequency (running or walking), and back pain history. We found that the average body weight was $60 \mathrm{~kg}(45-66.8 \mathrm{~kg})$ with BMI dominated by the normal categories $(58.9 \%)$. These results are similar with Chen et al which was $37.4 \%{ }^{6}$ Park et al examined the relationship between BMI and piriformis muscular abnormalities in inactive populations through
Computed Tomography (CT) imaging and concluded that an increase in BMI resulted increase in the distance between the piriformis muscle and the surrounding subcutaneous tissue. ${ }^{6,9}$ These abnormalities might trigger the occurrence of piriformis syndrome. However, the correlation between the incidence of piriformis syndrome and the increase in BMI still requires further study.

Ocupation history is one of the factors studied as a risk factor. Activities such as housewives (55.4\%) and field workers $(29.2 \%)$ were the most professions compared to office work or unemployed. Activities as housewives and field workers can be attributed to daily activities such as long standing, bowing and lifting objects. It may be caused by activation of the piriformis muscle even though there is no evidence linking the above activity with piriformis muscle activation. Syed et al found insignificant differences in working and non-working women related low back pain caused by piriformis syndrome. ${ }^{10}$

Majority of patients had history of repetitive microtrauma in the form of sitting on rigid surfaces $(36.9 \%)$ while the history of cross-legged sitting was only obtained in (10.8\%) samples. While the most average duration of sitting is 6-8 hours a day $(47.7 \%)$. Long duration of sitting might be as a predisposing factor for piriformis syndrome, supported by the study of Carro et al and Mondal et al (2017). ${ }^{4,11}$ However, both studies did not correctly state the duration of sitting a day which could be considered as a predisposing factor. Park et al concluded that inactive populations who sit more frequently for long periods (duration $\geq 8$ hours) have a tendency to experience lower back pain than other populations. ${ }^{9}$ Sitting for a long duration of time causes the muscles in the back and pelvis such as harmstring, iliopsoas, and piriformis to experience continuous contractions with little energy to maintain a position. Piriformis muscles that experience continuous contractions will experience stress on the sciatic nerve and cause sciatica irritation and pain as a symptom of piriformis syndrome. ${ }^{4}$

Piriformis muscle belongs to the type of postural muscle which has a tendency to tend to be hyperactive, hypertonic, weak, and short. Piriformis muscles work hyperactively and hypertonic during long sitting and walking. When there is weakness in the primary muscle that is responsible for certain joint movements, other synergy muscles will compensate for the work of the primary muscle. The main functions of the piriformis muscle is the external rotation of the pelvis and as a muscle synergy of the gluteus muscle during pelvic abduction. The long duration of sitting habits results in the weakness of the gluteus muscle and results in excessive activation of muscle synergy, piriformis musculus. Excessive muscle activation results in muscle weakness, muscle contraction and soft tissue damage. This explains the possibility of anomalies in the piriformis musculus that trigger piriformis syndrome. Besides that, the habit of sitting cross-legged activates the piriformis muscle to produce flexion of the pelvic movement and external rotation. Piriformis muscle will experience $21 \%$ elongation in cross-legged sitting position compared to standing position. If it lasts for a long time, this condition may produce muscle stiffness that results in coordination in muscle movement that triggers injury to the piriformis muscle. ${ }^{9}$ 


\section{Conclusion}

In conclusion, this study shows elderly and housewives characteristics differ with other studies. History of repetitive microtrauma may correlate with the onset of piriformis syndrome. Predisposing factors include female, age, normal BMI, and history of microtrauma.

\section{Acknowledgement}

The author thanks to Pelita Harapan University and Siloam Hospitals Lippo Village, Karawaci, Tangerang, Indonesia for facilitating this research.

\section{References}

1. Scott DD, Anderson LC. The piriformis syndrome: A review. J Back Musculoskelet Rehabil; 2014.4(3):248-54. DOI: 10.3233/BMR-1994-4314

2. Singh U, Meena R, Singh CA, Singh AKJ, Singh AM, Langshong R. Prevalence of piriformis syndrome among the cases of low back/buttock pain with sciatica: A prospective study. J Med Soc; 2013.27(2):94. DOI: 10.4103/0972-4958.121573

3. Jankovic D, Peng P, Van Zundert A. Brief review: piriformis syndrome: etiology, diagnosis, and management. Can J Anesth; 2013.60(10):1003-12. DOI: $10.1007 / \mathrm{s} 12630-013-0009-5$

4. Mondal M, Sarkar B, Alam S, Das S, Malik K, Kumar $\mathrm{P}$, et al. Prevalence of piriformis tightness in healthy sedentary individuals: a cross-sectional study. Ijsr; 2017.7(July):134-42. Available from: https://www.researchgate.net/publication/318318389_ Prevalence_of_Piriformis_Tightness_in_Healthy_Sed entary_Individuals_A_Cross-Sectional_Study

5. Demirel A, Baykara M, Koca TT, Berk E. Ultrasound elastography findings in piriformis muscle syndrome.
Indian J Radiol Imaging; 2018.28(4):412-8. DOI: 10.4103/ijri.IJRI_133_18

6. Kean Chen C, Nizar AJ. Prevalence of piriformis syndrome in chronic low back pain patients. a clinical diagnosis with modified fair test. Pain Pract; 2013.13(4):276-81. DOI: $\quad 10.1111 /$ j.15332500.2012.00585.x

7. Dey S, Brattacharayya, Das S. Piriformis syndrome: a clinical review. J Evol Med Dent Sci. 2013. 2(15):2505-8. DOI: 10.14260/jemds/568

8. Sivrioglu AK, Ozyurek S, Mutlu H, Sonmez G. Piriformis syndrome occuring after pregnancy. BMJ Case Rep. 2013:bcr2013008946. DOI: 10.1136/bcr2013-008946

9. Irshad S, Malik AN, Anwar S. Lumbar postural syndrome; Effectiveness of piriformis stretching with hip rotation. Professional Med J. 2016;23(10):1232-6. DOI: $10.17957 / \mathrm{TPMJ} / 16.2971$

10. Imtiaz S, Shah H, Muneer S. Prevalence of piriformis syndrome in working and non working women with low back pain. J Riphah Coll Rehabil Sci. 2014;2(2):6-11. Available from: https://www.ejmanager.com/mnstemps/130/1301423737108.pdf? $\mathrm{t}=1556520553$

11. Carro LP, Hernando MF, Cerezal L, Navarro IS, Fernandez AA, Castillo AO. Deep gluteal space problems: Piriformis syndrome, ischiofemoral impingement and sciatic nerve release. Muscles Ligaments Tendons J. 2016;6(3):384-96. DOI: 10.11138/mltj/2016.6.3.384

12. Sunarti S, Hariyanti T, Chriswantara RT. Physical activities, sitting time and frailty syndrome in elderly (a cross sectional study among elder person by fried criteria. Malang Neurology Journal; 2018.4(2):59-64. DOI: http://dx.doi.org/10.21776/ub.mnj.2018.004.02.3 